\title{
A novel route to process rationalisation on cellulose dyeing
}

\author{
Md. Nahid Pervez ${ }^{1,2,3}$, Mohammed Akramul Hoque ${ }^{3}$, Liping Yu ${ }^{4}$, Md. Moshfique Hossain Rinkon ${ }^{3}$, Md. Salman Amin ${ }^{3}$, Md. \\ Nazmul Ehsan ${ }^{3}$ and Yingjie Cai ${ }^{1,5}$ \\ ${ }^{1}$ School of Chemistry and Chemical Engineering, Wuhan Textile University, Wuhan 430073, China \\ ${ }^{2}$ Research Institute of Flexible Materials, School of Textiles \& Design, Heriot-Watt University, Galashiels TD1 3HF, UK \\ ${ }^{3}$ Department of Textile Engineering, Southeast University, Dhaka 1213, Bangladesh \\ ${ }^{4}$ Zhejiang Institute of Modern Textile Industry, Shaoxing 312000, China \\ ${ }^{5}$ Hubei Provincial Engineering Laboratory for Clean Production and High Value Utilization of Bio-based Textile Materials, Wuhan Textile \\ University, Wuhan 430073, China
}

\begin{abstract}
This research work presents an altercation on dyeing machine controlling parameters, particularly in terms of the relation between the effect of different factors i.e. reel speed $\left(\mathrm{m} \mathrm{min}^{-1}\right)$, cycle time (min), pump pressure (\%) and nozzle position $(\%)$ on color strength $(\mathrm{K} / \mathrm{S})$ property of different type's cotton fabric, so only the process controlling parameters were varied; the material used for the study remained the aforementioned throughout. The optimum reel speed, cycle time, pump pressure and nozzle position were found to be $240 \mathrm{~m} \mathrm{~min}^{-1}, 2.5 \mathrm{~min}, 60 \%$ and $70 \%$ respectively for winch dyeing machine with respect to cellulose materials. This work is useful in selecting optimum values of various controlling parameters that would not alone approve the process rationalisation but as well reduce the fabric consumption and advance the superior of the dyed fabric on applied imminence.
\end{abstract}

\section{Introduction}

Dyeing is the third important but a lot of circuitous action and it is a part of the key causes in the boastful trading of textile products than weaving and spinning, which is added an artwork than a science $[1,2]$ and it encompass three steps together with the diffusion of dye through the aqueous dye bath on to the fiber, the adsorption of dye into the outer layer of the fiber and the diffusion of dye from the adsorbed surface into the fiber interior. It goes after adage that, use of affection knitted fabric has been accretion in apple wide. People around each corner of the world, each custom, casts feel comfortable wearing cotton knitted fabric due to able applicable properties, softer handle backdrop and high extension at low tension compared to woven manufactured fabric [3]. By means of these excessive traits, knitted surfaces were apparently acclimated to woven materials. Reactive dyes are soluble anionic dyes which, in solution, are repelled by the negatively charged surface of the cotton fibre; this dyeclass has become more accepted [4]. That is mainly due to high levels of washing fastness, a wide gamut of bright colours, and versatility for altered appliance methods. The high fastness to washing of reactive dyes is due to their unique reactive groups, which forms covalent bonds with the hydroxyl groups of the cotton cellulose under alkaline $\mathrm{pH}$ conditions. It aswell supports dye assimilation into the fibre autogenously (diffusion) which leads to bigger dye fixation A salt such as sodium chloride or sodium sulphate is added as an electrolyte to advance the dye alteration (exhaustion) to the fibre. There are greater than $50 \%$ of cellulosic fibers are dyed with reactive dyes. Market share of reactive dyes among all textile dyes captured about $29 \%$. As a result of their strong bonding with many surfaces of synthetic and usual materials, reactive dyes are also used for dyeing wool, nylon, silk, and modified acrylics [5-7]. In an effort to achieve the specified dyeing first-rate, all causes that may impact the dyeing system need to be exactly controlled. As a consequence, it is wanted to improve productiveness and profitability of the field via making a choice on the various process controlling parameters. The principles of system manipulate measures are becoming preferred now days due to two main factors: (I) growing competitions and increasing cost of creation. (II) Fabric enterprise now a day is dealing with awfully stiff competitors. This competition is at macro and micro degree. Underneath these situations, cost and first-rate turns into fundamental standards, as a consequence, approach manipulate becomes more predominant, for reaching overall success. In literature, only a limited number of studies have been published about dyeing parameters and their effect on fabric properties [8-10]. However, no report yet published about influence of dyeing machine controlling parameters on dyeability of cotton fabric.

The current paper is intended to fill the missing link in the above papers and to discuss the application of control equipment; in particular parameters i.e. reel speed $\left(\mathrm{m} \min ^{-1}\right)$, cycle time ( $\left.\mathrm{min}\right)$, pump pressure $(\%)$ and nozzle position (\%) effect on cellulose dyeing on lab scale. 


\section{Experimental}

\subsection{Materials}

Commercially available three different knit structures based cotton fabrics were used throughout the study. Remazol Red RR (MCT-VS dye), $\mathrm{Na}_{2} \mathrm{SO}_{4}, \mathrm{Na}_{2} \mathrm{CO}_{3}$, $\mathrm{NaOH}$, soaping agent and acetic acid were supplied by supplied by local chemicals company and are laboratory grade.

\subsection{Dyeing procedure}

The optimized dyeing process of fabrics with Remazol Red RR dye was performed at 5\% shade and 1: 50 liquor ratio in exhaust process via winch dyeing machine (Figure 1). The fabrics were bathed inside the dyeing solution at room temperature followed by addition of 30 $\mathrm{g} \mathrm{L}^{-1}$ of salt. In the meantime, the temperature was kept at $25^{\circ} \mathrm{C}$ and the dyeing process was continued for 30 minutes. Then $20 \mathrm{~g} \mathrm{~L}^{-1}$ of $\mathrm{NaOH}$ was added to the dyeing bath and stayed for additional 30 minutes. The final dyed fabrics were neutralized with $2.5 \mathrm{~g} \mathrm{~L}^{-1}$ of acetic acid followed by rinsing with excess water until the final rinse become colorless.

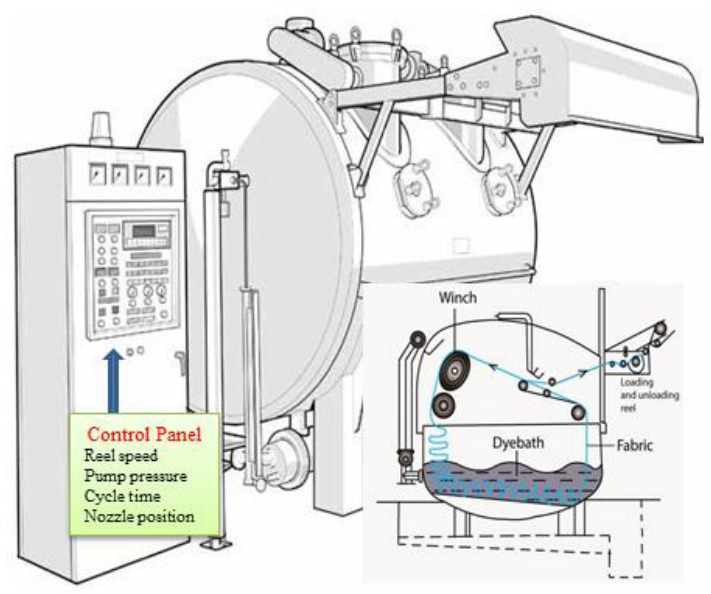

Figure 1. Schematic diagram of Winch Dyeing $M / c$ (Inside view)

During optimized dyeing process, for the optimization of dyeing machine controlling parameters i.e. reel speed $\left(\mathrm{m} \mathrm{min}{ }^{-1}\right)$, cycle time (min), pump pressure $(\%)$ and nozzle position (\%) were carried out at different variables. At first, experiments were carried out to optimize dyeing reel speed varies at $220-260 \mathrm{~m} \mathrm{~min}^{-1}$. To understand the effect of cycle time, another set of experiments were carried out in optimized cycle time for different time periods that are 2.20-2.60 minutes. Another set of experiments were also carried out at different pump pressure such as 40-60\%. In case of nozzle position, the experiments were also accelerated in different variables at 40-80\%. After dyeing, the dyed samples were rinsed with cold water and washed in a bath with a liquor ratio of 1: 50 using $1 \mathrm{~g} \mathrm{~L}^{-1}$ of the soaping agent at $60^{\circ} \mathrm{C}$ for 10 minutes and then they were again rinsed and finally dried in a dryer. Based on the color strength $(\mathrm{K} / \mathrm{S})$ values of the dyed samples, optimum dyeing machine parameters such as reel speed, cycle time, pump pressure and nozzle position were selected.

\subsection{Colour strength evaluation}

The colour strength and the reflectance spectra of all the dyed fabrics were measured using a UV vis spectrophotometer. The colour strength $(\mathrm{K} / \mathrm{S})$ value was calculated using Equation 1 given below

$$
\frac{\mathrm{K}}{\mathrm{S}}=\frac{(1-\mathrm{R})^{2}}{2 \mathrm{R}}
$$

Where $\mathrm{K}$ is the coefficient of absorption, $\mathrm{S}$ is the coefficient of scattering; and $\mathrm{R}$ is the reflectance value of the fabric at max.

\section{Results and discussion}

For purpose to describe the process expediently and to determine the optimum parameters we assess the effect of each parameter at variable values. The $\mathrm{K} / \mathrm{S}$ values which are considered as representations of color strength were measured and the results are discussed in order hereinafter.

\subsection{Effect of reel speed on color strength (K/S)}

In winch dyeing machine, winch reel not only controls the rate of movement of the fabric rope, but also the configuration of the rope in the dye bath. It does not grip the fabric positively, but by the weight of the wet fabric and the friction between the reel and fabric. The speed of reel can be calculated according to Equation 2.

$$
\text { Reel } \text { speed }=\frac{\text { Fabric weight }}{\text { GSM } \times \text { Fabric Width } \times \text { Cycle Time } \times \text { Nozzle }}
$$

As shown in Figure 2, it is clear that the color strength values had been accelerated with expand of reel speed and reaches a highest value at $240 \mathrm{~m} \mathrm{~min}^{-1}$ then it decreases slowly because excessive speed explanations a gigantic lengthwise stretching stress and pull on the fabric being dyed which is unsafe to best [11]. The effect of reel speed of dye bath can also be attributed as a result of special resonating varieties of dye molecules i.e. heterogeneous distribution of dyes and the interaction between coloring component and pore size of cotton fibers used and the better kinetic vigour of the dye molecule, the fiber swelling characteristic and availability of the significant number of energetic binding sites onto the outer surface of cotton molecules. Additionally, a big amount of water exists within the interfibres and interyarns or even on the fabric surface at this time, which may cause severe reactive dye hydrolysis [12] and further reduce the $\mathrm{K} / \mathrm{S}$ value. The dyestuff is present in the solution as single molecules as well as aggregates. Increasing the speed leads to the breaking down of aggregates. So, the numbers of single molecules existing within the solution emerge as raises. When single molecule absorbed through the fiber, additional hydroxyl 
groups consider from the aggregates, which can be, taken up via material, leading to a complete even dyeing [13].

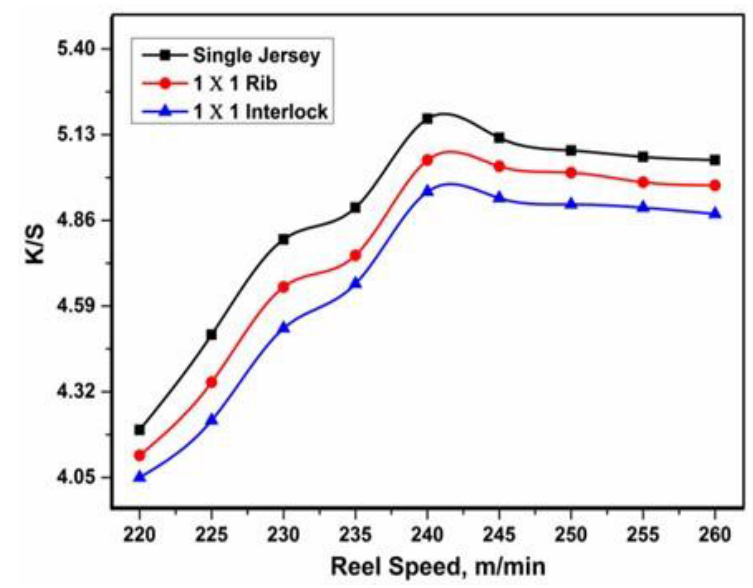

Figure 2. Effect of reel speed on color strength (K/S)

\subsection{Effect of cycle time on color strength $(\mathrm{K} / \mathrm{S})$}

In exhaust dyeing method cycle time is important factor. The time required to move the whole loop is termed as cycle time and it can be measured by Equation 3 .

$$
\text { Cycle time }=\frac{\text { Meters per Chamber }}{\text { Reel speed }}
$$

The relationship between dye adsorption and cycle time in cellulose dyeing is demonstrated in Figure 3. It is seen that dye uptake expressed as color strength $(\mathrm{K} / \mathrm{S})$ increased with increasing cycle time and there is decrease in the colour strength after surpasses time $2.5 \mathrm{~min}$. The decline in colour strength is attributed to the shift in equilibrium of colouring component from fabric into dye bath during longer cycle time. In case of the advance in $\mathrm{K} / \mathrm{S}$ values reflected the absolute accept an effect on of increasing cycle time which concluded in an acceptable and compatible adsorption of the dye via the fibers, as acceptable as compatible assimilation and circulation of the dye into the material, which resulted in the accessory of the uptake of the dye into the material [14]. However, this result was not consistent with all fabrics, since the $\mathrm{K} / \mathrm{S}$ value of the single jersey plain knit fabric is higher than that of the other two type's fabric as shown in Figure 2. This may be attributed to the decomposition of the dye with prolonged time leading to a lower $\mathrm{K} / \mathrm{S}$ value and high stretching strain damage the material and tend to impart permanency to the wrinkles, and this often necessitates full width dyeing [11].

\subsection{Effect of pump pressure on color strength (K/S)}

The pump generates static stress, which may also be infinitely adjusted and remains constant throughout treatment, irrespective of the temperature. Machine topping up may also be completed at any time making use of the stress pump. The effect of pump pressure (\%) on the colour strength of the dyed cotton fabrics is illustrated in Figure 4. It can be seen clearly that both the $\mathrm{K} / \mathrm{S}$ value increased markedly with increasing pump pressure when it was shorter than $60 \%$. Thus, the access in the $\mathrm{K} / \mathrm{S}$ ethics may be activated with the access in the apparent acerbity and wettability of a fabric, which may access its water swelling capability and its affection for acknowledging dyes. However, if the pump burden exceeded $60 \%$, the accretion trend of the $\mathrm{K} / \mathrm{S}$ amount began to decline. Results can be explained from thermodynamic attempt acquiescent the clapeyron effect. A pressure was activated assimilate the fabric during dyeing to ensure activity manual and bonding amid the fabric surfaces. This pressure creates a hot compaction on the fibers that affects the bonding amid the fabric layers. It is sometimes abominably believed that high pressure is essential to accomplish a high liquor flow through the material. The rate of flow of liquor is determined by the accommodation of the pump and by the aberration in pressure immediately before and beyond the wound package, known as the differential pressure. In general, the lower the attrition of the actual to an assertive pump, the lower the differential pressure and the higher the flow [15]. At low pressure poor transmission of energy takes place, and consequently, fabric color strength does not ability to the appropriate akin and the fiber acclimatization is as well not maintained due to abridgement of constraint. Under acceptable pressure, fibers are aseptic from shrinking and loosing acclimatization consequently, application the fiber strength and announcement able bonding [16].

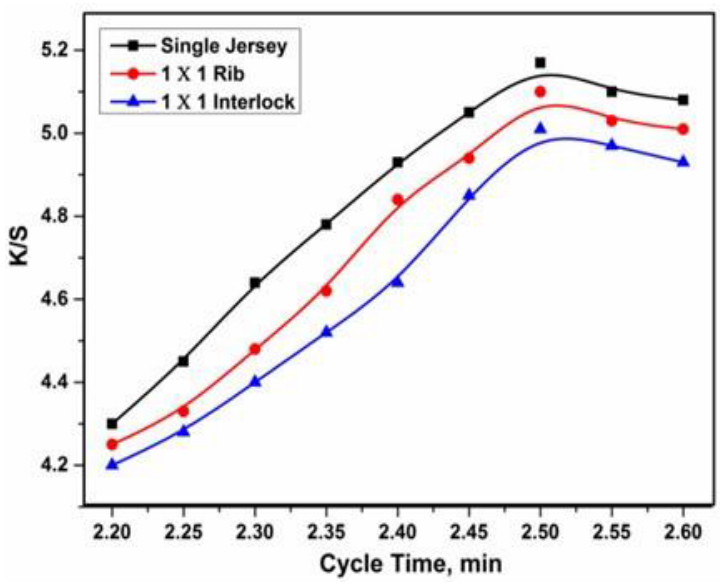

Figure 3. Effect of cycle time on color strength (K/S)

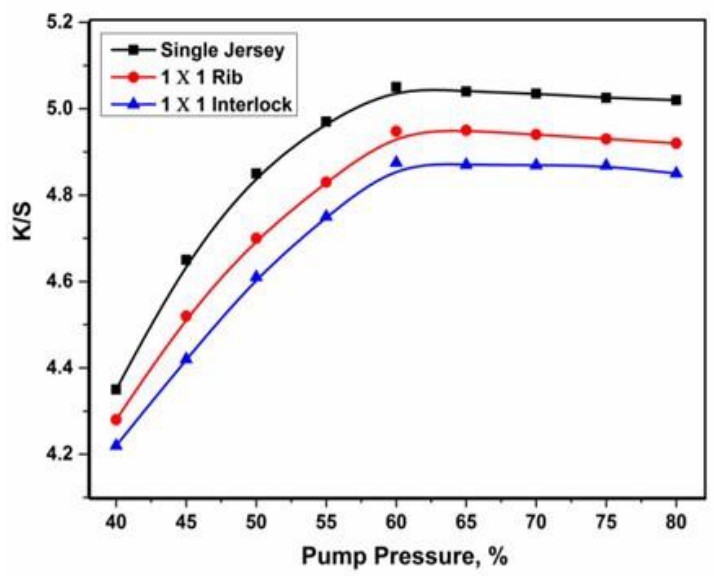

Figure 4. Effect of pump pressure on color strength (K/S) 


\subsection{Effect of nozzle position on color strength (K/S)}

A nozzle accumulation for a fabric dyeing apparatus comprises a tubular nozzle affiliate through which fabric travels, the nozzle affiliates authentic by four ancillary walls and accepting an ellipsoidal cross-section, and a nozzle gap in an ancillary bank of the nozzle affiliate through which aqueous can be activated to fabric in the nozzle affiliate to actuate the fabric along a travel path [17]. The effect of nozzle position (\%) on the colour strength of the dyed cotton fabrics are shown in Figure 5. It can be seen clearly that both the $\mathrm{K} / \mathrm{S}$ value increased markedly with increasing nozzle position when it was shorter than $60 \%$ but abruptly decreased values after $60 \%$ and claim maximum $\mathrm{k} / \mathrm{s}$ values at $70 \%$. The design of such a nozzle can be challenging. On one hand, the nozzle should not absorb too abundant space, as this would yield up too abundant aqueous aggregate within the machine and affect the liquor ratio (ratio of the volume of dye liquor to the weight/amount of fabric that is required to produce a desired dyeing result). To accomplish an even dyeing effect, it is adorable that the fabric braiding opens beyond the amplitude of the fabric during dyeing, and changes position each time it passes through the nozzle. This provides an able and even appliance of dye liquor assimilate and into the fabric. However, a circular nozzle tends to clasp and abbreviate the fabric casual through it rather than acceptance the fabric to extend width-wise. The assay helps in compassionate the beginning results. The nozzle position of the ejector influences the ejecting accessory a lot. The optimum nozzle position of the subsonic ejector exists if the flow and added geometry ambit are fixed. The ejecting accessories will ability its best when setting the nozzle at the optimum position, and abatement if deviating. The optimum nozzle position of an ejector is not constant; but is a variable, afflicted abundantly by the flow ambit [18].

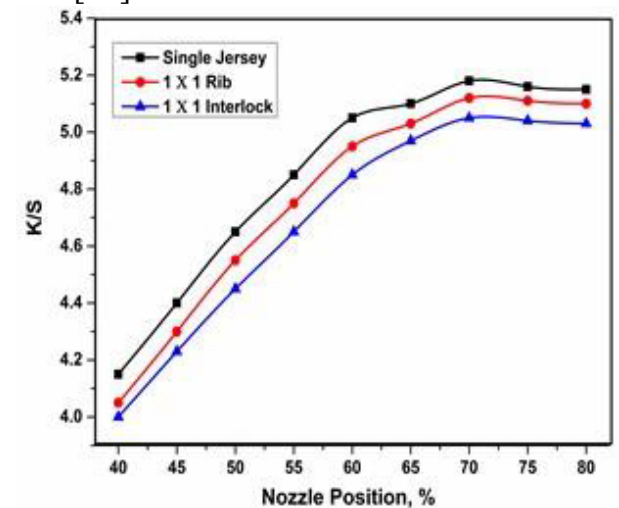

Figure 5. Effect of nozzle position on color strength $(\mathrm{K} / \mathrm{S})$

\section{Conclusion}

The study reveals a cogent access of process variables, namely reel speed, cycle time, pump pressure and nozzle position on knit structures based cotton fabric color strength property. The after-effects acquired in this plan adumbrated that the optimization of machine controlling parameters can be an important footfall in acceptable textile dyeing with respect to the energy savings that implemented by an aggregate of action process parameters using dyeing principles. This embodiment provides meaningful production data for the effective development of added assorted dyeing industry accompanying products along with the localization of accomplishment for absolute garments.

\section{Acknowledgement}

This work was financially supported by the China National Textile \& Apparel Council (2013 "Textile Vision" Applied Basic Research, 2013-153); Hubei Province Science and Technology Support Program (Grant No. 2013BAA043) and the Collaborative Innovation Plan of Hubei Province for Key Technology of Eco-Ramie Industry (2014-8).

\section{References}

1. T. Hussain, R. Wardman, R. Shamey, Coloration Technology. 121, 53 (2005)

2. M.N. Pervez, M.A. Rahman, International Journal of Scientific \& Engineering Research. 6, 660 (2015)

3. N. Anbumani, Knitting Fundamentals, Machines, Structures and Developments, New Age International, (2007)

4. Holme, I., Dyeing cellulosic fibres. Text. Mag. 318 (2004).

5. M.O. Bulut, K. Akçali, Oktav Bulut ve Akçalı, Erciyes Üniversitesi Fen Bilimleri Enstitüsü Dergisi. 30, 39 (2016)

6. L. Lin, M.Z. Rahman, S. Wen, M.N. Pervez, J. Li, Y. Cai. Improvement of color fastness for deep black shade of cotton fabric. in 4th International Conference on Machinery, Materials and Computing Technology. China: Atlantis press. (2016)

7. M.M.R. Khan, A. Islam, M.A. Habib, M.N. Pervez, International Journal of Scientific \& Engineering Research. 6, 19 (2015)

8. I. Hossain, A. Hossain, I.A. Choudhury, The Journal of the Textile Institute. 107, 1 (2016)

9. K. Ojha, R. Sharma, S. Pathak, Journal of Mechanical Design and Vibration. 2, 74 (2014)

10. M.A. Jahid, M.N. Pervez, American Journal of Materials Science. 5, 57 (2015)

11. V.C. Bohm, Dyeing apparatus. 1955, Google Patents: USA.

12. Z. Mao, H. Yu, Y. Wang, L. Zhang, Y. Zhong, H. $\mathrm{Xu}$, Industrial \& Engineering Chemistry Research. 53, 8927 (2014)

13. V. Shenhnai, Technology of textile processing (Sevak publications, 1976)

14. P.J. Hauser, Textile technology (Intech open access publisher: Croatia, 2011)

15. P. Horn, Journal of the Society of Dyers and Colourists. 81, 262 (1965)

16. J. Ibar, Polymer Engineering \& Science. 38, 1 (1998)

17. A.T. Jr, Apparatus for wet-treating fabrics. 1977, U.S. Patents 4,020,658.

18. T.W.T. Ming, Nozzle for jet fabric dyeing machine. 2007, European Patents 1988205 A1. 